\title{
Evaluating Lynch syndrome in very early onset colorectal cancer probands without apparent polyposis
}

\author{
Kory W. Jasperson ${ }^{1,2}$, Thuy M. $\mathrm{Vu}^{3}$, Angela L. Schwab ${ }^{2}$, Deborah W. Neklason ${ }^{2}$, Miguel A. \\ Rodriguez-Bigas $^{3}$, Randall W. Burt ${ }^{2}$, and Jeffrey N. Weitzel ${ }^{1}$ \\ ${ }^{1}$ Cancer Screening \& Prevention Program, City of Hope Cancer Center, Duarte, California \\ ${ }^{2}$ Huntsman Cancer Institute, University of Utah, Salt Lake City, Utah \\ ${ }^{3}$ Department of Clinical Cancer Genetics, University of Texas MD Anderson Cancer Center, \\ Houston, Texas
}

\begin{abstract}
Aim-To characterize the frequency of germline mutations associated with Lynch syndrome and review the potential expanded differential diagnoses in very early onset colorectal cancer (CRC) cases without apparent polyposis.
\end{abstract}

Methods-Retrospectively reviewed medical records of 96 probands with CRC diagnosed prior to age 36 from three cancer centers. Determined the frequency of germline mutations in probands meeting different clinical criteria used to identify Lynch syndrome.

Results-Three of 46 (6.5\%) single case indicators (probands without additional personal or family history suspicious for Lynch syndrome) were identified to carry a deleterious or suspected deleterious mismatch repair (MMR) mutation compared with 10 of $19(52.6 \%)$ in the cases meeting at least one additional revised Bethesda guideline, and 11 of $15(73.3 \%)$ in the cases meeting Amsterdam criteria. Two families without MMR mutations were documented to have a germline $A P C$ or TP53 mutation after additional clinical features were identified.

Conclusions-Our results suggest that single cases of CRC (those without additional personal or family history suspicious of Lynch syndrome) diagnosed prior to age 36 infrequently have identifiable MMR mutations, especially when compared to cases meeting additional criteria. Careful attention to evolving or additional clinical features is warranted and may lead to an alternate genetic diagnosis in families with early onset CRC.

\section{Keywords}

Attenuated familial adenomatous polyposis; Early onset colorectal cancer; HNPCC; Genetic testing; Li-Fraumeni syndrome; Lynch syndrome; Mismatch repair genes

\section{Introduction}

Lynch syndrome, also known as hereditary non-polyposis colorectal cancer, is an autosomal dominant condition associated with up to an $80 \%$ lifetime risk for colorectal cancer (CRC) and increased risk for other associated malignancies [1,2]. One of the hallmark features of Lynch syndrome is the relatively early age of CRC diagnosis. The average age of CRC onset in Lynch syndrome is in the mid 40s, which is decades earlier than the average age seen in

Correspondence to: Kory Jasperson, Huntsman Cancer Institute, 2000 Circle of Hope, Room 3145, Salt Lake City, Utah 84112, kory.jasperson@hci.utah.edu Ph: (801) 581-7316 Fax: (801) 585-2980. 
the general population [1, 3-7]. Given the propensity for early onset CRC, age of onset was included in the original Amsterdam criteria (AC I) devised to identify families suspicious for Lynch syndrome [8]. The criteria are defined by at least three individuals with CRC, two successive generations with one individual being a first degree relative of the other two and at least one diagnosis prior to age 50, while the Amsterdam criteria II includes extra-colonic tumors such as endometrial cancer $[8,9]$. Guidelines to help facilitate the diagnosis of Lynch syndrome have evolved over the years, while age of onset continues to be a defining criterion $[2,9,10]$. The revised Bethesda guidelines (BG; see Appendix) are currently used to identify individuals suspicious for Lynch syndrome and therefore appropriate for further evaluation [2].

Very early age of CRC onset, defined here as a diagnosis 35 years of age or younger, is an area of active interest for researchers and clinicians. Previous studies have revealed that probands with CRC diagnosed at these early ages have a high probability of having a germline MMR mutation [11-15]. Although early age of onset combined with additional features may result in a high probability of having Lynch syndrome, limited data exist as to the likelihood of finding a germline MMR mutation in very early onset CRC cases in the absence of additional personal or family history of Lynch syndrome-associated tumors. Even though limited data exists regarding the chance of finding a mutation in these early onset cases, it has been suggested that the evaluation of Lynch syndrome, regardless of family history, should begin with germline genetic testing versus screening with microsatellite instability (MSI) and/or immunohistochemistry (IHC) [13].

Here we characterized the frequency of germline MMR mutations in CRC cases diagnosed prior to age 36, without apparent polyposis. Also reviewed are the potential expanded differential diagnoses of MYH-associated polyposis (MAP), attenuated familial adenomatous polyposis (AFAP) and Li-Fraumeni syndrome.

\section{Methods}

\section{Patient selection and data collection}

Probands with CRC diagnosed prior to age 36 years were ascertained from hereditary cancer registries at the University of Texas MD Anderson Cancer Center, City of Hope National Medical Center, and Huntsman Cancer Institute at the University of Utah. Patients are recruited into each institutional review board approved hereditary cancer registry through the corresponding cancer genetics program. In addition to the cancer registry, probands from Huntsman were also identified via a CRC research study using the Utah Population Database (UPDB). The UPDB is a genealogic resource linked to state wide cancer registry data [16]. Individuals referred to any site due to a known germline genetic mutation were excluded. Probands with greater than 10 adenomatous colonic polyps at time of evaluation were also excluded to eliminate individuals with a clinically apparent polyposis syndrome.

For each proband, data were retrospectively collected on CRC tumor histology and location, number and histologic type of colonic polyps, additional personal cancer history, and family medical history. Detailed family history information (relatives' current age, age at death and cause of death, medical problems including cancer history and other neoplasms) was obtained by cancer genetic specialists via patient report and medical records, whenever available. For a subset of the Huntsman cohort, family histories were also obtained from genealogy records available through the UPDB. Demographic data, genetic testing, MSI, and IHC tumor testing results were also collected from patient charts. 


\section{Testing strategies}

Probands were evaluated by the respective centers from 1997 to March 2007. A variety of techniques were utilized to assess for Lynch syndrome including; personal and family medical history review, tumor analysis (MSI and/or IHC), and/or germline genetic testing of the MMR genes. Testing strategies varied for each proband based on a number of different factors including, but not limited to, the center they were seen at, the availability of testing methodologies at the time they were evaluated and patient preference. All individuals identified through the UPDB had MSI analysis with or without IHC studies. Individuals with abnormal tumor analysis were offered genetic testing to identify the germline defect, if one was present. For probands identified through the cancer registries, testing strategies either began with tumor analysis or germline genetic testing of $h M L H 1$ and $h M S H 2$. Genetic testing of $h M L H 1$ and $h M S H 2$ consisted of sequencing of all exons and adjacent introns by standard clinical techniques. Depending on patient preference and technologies available at time of evaluation, genetic testing may have also consisted of sequencing of $h M S H 6$ and rearrangement studies of $h M L H 1$ and $h M S H 2$.

Probands with MSI-high (MSI-H) tumors and absent IHC staining for hMSH2, were assumed to have a germline MMR defect. Individuals with MSI-H tumors, absent staining for hMLH1, and no follow up MMR genetic testing were not included in the statistical analysis evaluating mutation frequencies. Molecular analysis of these probands was deemed uninformative as somatic hypermethylation of $h M L H 1$ versus a germline defect could not be differentiated based on the available results. In addition, probands with tumors showing MSI-low or MSI-stable and/or normal staining of the MMR proteins by IHC analysis, were assumed to be negative for MMR germline mutations. This assumption is based on the high sensitivity of detecting a germline MMR mutation when using MSI and/or IHC analysis [17-19].

\section{Personal and family history}

Using personal and family history data, probands were categorized based on whether they met certain BGs or AC. By definition, all probands included in this study met BG I, as each had a diagnosis of CRC prior to age 50. Probands that did not meet additional personal or family history criteria were categorized as 'single case indicators'. We also categorized probands using additional personal history of cancer (BG II). Probands in the category 'any Bethesda guideline' met BG II, IV and/or V, but did not meet AC. Certain categories are not mutually exclusive, as probands that were included in the category revised Bethesda guideline II, may have also been included in the categories Amsterdam criteria or any Bethesda guideline. BG III (CRC diagnosed prior to age 60 and the presence of MSI-H histology) was not considered separately due to potential differences in reporting across the three cohorts.

\section{Statistical analyses}

Differences in the clinical characteristics and demographics among the three centers were compared with chi-square test for categorical variables and one-way ANOVA for continuous variables. Pearson chi-square test was used to compare the differences in mutations rates among the three centers. All statistical tests were two-sided and differences were considered significant if $P<0.05$. Statistical analyses were performed using SPSS version 14 and SAS version 9. 


\section{Results}

\section{Clinical characteristics and demographics}

A total of 96 probands with CRC diagnosed prior to age 36 were included in the study; their clinical characteristics and demographics are summarized in the Appendix. A small number of probands did not have a pathology confirmation of their CRC diagnosis or family history information available. No statistically significant differences were found among the three centers with respect to gender, age of CRC diagnosis, associated histology, or family history criteria met. However, significantly fewer individuals had right sided CRC tumors in the Huntsman cohort $(\mathrm{P}<0.026)$.

The average age of CRC onset was 29.4 years with the earliest diagnosis occurring at age 18 years. Nearly half (44.7\%) of all CRC tumors occurred proximal to the splenic flexure and 31 of $90(34.4 \%)$ tumors revealed an MSI-H histology. At least three generations of family history data were available for 89 probands and $16(18.0 \%)$ of these met AC I and/or II, 25 (28.1\%) met BG II, IV and/or V, and 48 (53.9\%) were classified as a single case indicator.

\section{Relationship of testing strategies to molecular results}

The results of molecular testing strategies are summarized in Table 1. Probands were stratified based on clinical criteria met and further categorized based on whether testing strategies for Lynch syndrome started with MSI and/or IHC analysis (somatic approach) versus germline genetic testing (germline approach). The number of individuals that underwent each testing strategy is summarized in Table 1. Cases with abnormal tumor results (MSI-H or absent staining of MLH1 protein by IHC analysis) but without follow up germline genetic testing, were not included in the last two columns of Table 1. In addition, three probands did not proceed with any testing for Lynch syndrome, and therefore were not included in Table 1.

Of the 96 probands included in this study, 86 had an adequate evaluation for Lynch syndrome and $25(29.1 \%)$ of these were found to have a deleterious mutation or suspected mutation in a MMR gene. Out of the 16 cases that met AC I or II, 13 started with tumor analysis while three cases went directly to germline genetic testing of $h M L H 1$ and $h M S H 2$. One of the probands that started with tumor analysis did not have an adequate evaluation due to lack of follow up genetic testing. This proband was excluded from the last two columns of Table 1 . Out of the 15 probands that met $\mathrm{AC}$ and had an adequate evaluation, 11 (73.3\%) were found to have a germline MMR defect and are listed in Table 2. Of the nine probands that met BG II, six (66.7\%) were found to have a germline mutation. There were 22 individuals that met 'any Bethesda guideline' and three of these did not have a complete evaluation. Of the 19 remaining probands, $10(52.6 \%)$ were found to carry germline mutations. Out of the 46 single case indicators with a complete evaluation, only three (6.5\%) were found to have germline MMR defects. There were also six probands that underwent an adequate evaluation for Lynch syndrome but did not have family history data available (data not shown). Of these probands, one (16.7\%) was found to have an MSI-H tumor and absent staining of hMSH2.

Single case indicators were significantly less likely to have an identifiable germline MMR mutation than probands meeting $\mathrm{AC}$ or any $\mathrm{BG}(\mathrm{P}<0.001)$. No statistical differences were identified regarding mutation status between the probands in the any $\mathrm{BG}$ category versus those meeting $\mathrm{AC}(\mathrm{P}=0.191)$. In addition, no statistical differences were identified regarding mutation status and different center $(\mathrm{P}=0.202)$. 


\section{Mismatch repair mutations}

A total of 21 documented germline mutations and four suspected mutations within the MMR genes were identified (Table 2). Of the 21 documented germline mutations, 11 were in $h M L H 1$, nine in $h M S H 2$, and one in $h M S H 6$. One of the germline mutations in $h M S H 2$ was classified by the laboratory as a variant of uncertain significance. However, the absent staining of hMSH2 and hMSH6 by IHC analysis was highly suspicious for a germline mutation. The specific mutations were not available for certain probands due to IRB restrictions in sharing information for this study or lack of access to records. The four individuals with suspected germline mutations had MSI-H tumors, absent staining of hMSH2 and normal staining of hMLH1.

\section{Additional genetic testing}

After germline MMR mutations had been ruled out or was determined to be of low probability, a limited number of families underwent further molecular evaluation for AFAP, MAP or Li- Fraumeni syndrome. Two families were documented to have a genetic condition other than Lynch syndrome, and their clinical, molecular, and family characteristics are shown in Table 3.

Proband \#201 was found to have adenocarcinoma of the cecum at age 33 and no additional polyps at time of diagnosis. Esophagogastroduodenoscopy revealed a normal appearing duodenum and stomach. The family history was significant for multiple members with CRC and a sister with both CRC and uterine cancer. No family members were reported to have polyps. The family met AC and tumor analysis revealed an MSI-H tumor. Sequencing of $h M L H 1$ and $h M S H 2$ was normal. Four years after genetic testing of $h M L H 1$ and $h M S H 2$, the proband reported a brother with numerous gastrointestinal polyps, including both fundic gland polyposis and approximately 50 adenomas spread throughout the colon. Due to the history of polyps, the brother proceeded with $A P C$ genetic testing and was found to carry a deleterious mutation. The proband has not yet proceeded with genetic testing for the familial $A P C$ mutation, however subsequent colonoscopies have revealed multiple colon adenomas, consistent with a diagnosis of AFAP. The etiology of the proband's MSI-H colon tumor has not been resolved, as this tumor characteristic is not associated with AFAP.

Proband \# 218 had an osteosarcoma of the right tibia at age 14 and adenocarcinoma in the proximal colon at age 34 . The only history of cancer in his family occurred in the paternal lineage (see Table 3). Due to the early onset CRC, both MSI and IHC analyses were performed and the tumor results were normal. Given the normal tumor analyses and the history of osteosarcoma, germline genetic testing of TP53 was performed. The results revealed a deleterious TP53 mutation consistent with a diagnosis of Li-Fraumeni syndrome. At time of manuscript submission, family members had not been tested for the TP53 mutation to determine the possibility of a de novo mutation.

\section{Discussion}

Here we have evaluated the largest known cohort of CRC cases diagnosed prior to age 36 for germline mutations in the MMR genes. A total of 25 (29.1\%) documented or suspected MMR mutations were identified in the 86 probands with an adequate Lynch syndrome evaluation [11-15]. Previous studies have also found a high rate of germline mutations in very early onset CRC cases [11-15]. The detection rates of mutations in these studies are summarized in Table 4. Terdiman et al. [15] found no germline mutations in 16 probands tested from a population based registry and 13 out $21(61.9 \%)$ in probands from a high risk clinic. After adjusting for family history and other variables, medical institution remained an 
independent predictor of MMR defect [15]. Ascertainment bias is a likely explanation for this finding [15]. In our cohort, cancer center was not associated with mutation status.

The findings presented in Table 4 suggest that very early onset CRC cases frequently have MMR mutations. The assumed high likelihood of detecting a mutation has even been used to support testing strategies which begin with germline genetic testing (versus screening with MSI and/or IHC) in these young cases, regardless of family history [13]. However, in our cohort, when age was used as the sole testing indicator (single case indicators), only 3 of 46 (6.5\%) germline MMR defects were revealed. Our findings do not support a high likelihood of detecting a mutation in early onset CRC cases, unless there is additional personal or family history of Lynch syndrome tumors. Based on these findings, cost effective testing strategies beginning with tumor analyses should be considered in these early onset cases.

Although the average age of CRC onset in $h M L H 1$ and $h M S H 2$ mutation carriers has been estimated to be in the 40s $[1,5,7]$, recent studies have shown that $h M S H 6$ mutation carriers are diagnosed on average 10 years later [5, 21, 22]. Mutations in $h M S H 6$ have also been linked to a lower risk of CRC and a higher risk of endometrial cancer [5, 21, 22]. These differences in ages of onset and associated risk suggest that $\mathrm{hMSH6}$ mutations would constitute a minor fraction of very early onset CRC cases. However, we identified one germline $\mathrm{hMSH6}$ mutation in our cohort and this individual was a single case indicator. Pinto et al. [23] also identified a germline $h M S H 6$ mutation in an individual with very early onset CRC and no family history suspicious of Lynch syndrome was reported. These two cases highlight that $h M S H 6$ mutations should not be overlooked when evaluating early onset cases for MMR mutations.

A major limitation of this current study was the variability in testing methods used to evaluate for Lynch syndrome. Certain probands only had genetic testing of the $h M L H 1$ and $h M S H 2$ genes and therefore mutations in $h M S H 6$ and $h P M S 2$ may have been missed. Clinical genetic testing for mutations in $h P M S 2$ (a rare cause of Lynch syndrome) was not available during the time when probands were evaluated. Mutations in $h M L H 1$ and $h M S H 2$ may also have been missed in individuals where only sequencing was performed. In addition, not all probands undergoing tumor testing had both MSI and IHC analyses, which could result in a suboptimal detection rate. However, recent studies have suggested that MSI and/or IHC analysis is a highly sensitivity method for identifying Lynch syndrome, especially in early onset CRC cases [2,18-20]. Given that 39 out of $46(84.8 \%)$ of the single cases underwent tumor analysis, the limited number of mutation carriers identified in our cohort is likely to be an accurate reflection of the real detection rate in this group.

Inherited germline mutations in the MMR genes are the most frequent cause of hereditary CRC. Other hereditary cancer susceptibility genes, such as $A P C$ and $M Y H$ have also been implicated in early onset CRC cases without polyposis [24-27]. Germline mutations in TP53, associated with Li-Fraumeni syndrome, are another possible cause of early onset CRC [28]. Although no systematic analysis for germline mutations in these genes was conducted, one family was found to have Li-Fraumeni syndrome, while another was determined to have AFAP. These two families stimulate interesting hypotheses to the possible underlying genetic causes of early onset CRC. Proband \#218 is a fascinating case as the differential diagnoses included two very different hereditary cancer syndromes. The early onset CRC was suggestive of Lynch syndrome, however this possibility was deemed unlikely after MSI and IHC analyses came back normal. Given the diagnosis of osteosarcoma, Li-Fraumeni syndrome was also entertained and TP53 genetic testing revealed a deleterious mutation. This case supports recent findings that Li-Fraumeni syndrome predisposes to early onset CRC [28]. 
Often the feature that most easily distinguishes Lynch syndrome from individuals with $A P C$ mutations is the lack of colonic polyposis that is characteristic of individuals with germline MMR mutations. The family history of CRC for Proband \#201 was highly suggestive of Lynch syndrome given the absence of polyps originally reported in the family. After the brother was later found to have both fundic gland and colonic polyposis, the diagnosis of AFAP became apparent. This supports that careful attention to evolving or additional clinical features is warranted and may lead to an alternate genetic diagnosis in these young cases.

The increasing costs of molecular evaluation, the number of clinical tests available, the genetic heterogeneity, and the potential for differential diagnoses are a few of the factors that add to the complexity of evaluating early onset CRC cases for hereditary syndromes. Given these factors and the less than $10 \%$ chance of finding a mutation in single case indicators from our study, MSI and IHC analyses should be considered as the initial test, whenever possible, followed by germline genetic testing only when tumor analysis results reveal a likely MMR defect. Probands with early onset CRC and normal tumor analysis should be reassured that it is very unlikely that they have Lynch syndrome. Alternate genetic diagnoses are of concern in these early cases, although it is still unclear if germline defects in $M Y H, A P C$, or TP53 are responsible for a significant proportion of these non-Lynch syndrome CRC cases. Further studies are needed to better understand this genetically undefined group of early onset CRCs.

\section{Acknowledgments}

We would like to thank the expert input from Katrina Lowstuter MS, CGC regarding this manuscript. This research was supported in part by a General Clinical Research Center grant from NIH (M01 RR00043) and by the National Cancer Institute, Grant No. R25 CA85771.

\section{Abbreviations}

$\begin{array}{ll}\text { AC } & \text { Amsterdam criteria } \\ \text { AFAP } & \text { attenuated familial adenomatous polyposis } \\ \text { CRC } & \text { Colorectal cancer } \\ \text { IHC } & \text { Immunohistochemistry } \\ \text { MAP } & \text { MYH associated polyposis } \\ \text { MMR } & \text { Mismatch repair } \\ \text { MSI } & \text { Microsatellite instability } \\ \text { UPDB } & \text { Utah Population Database }\end{array}$

\section{References}

1. Aarnio M, Sankila R, Pukkala E, Salovaara R, Aaltonen LA, de la Chapelle A, Peltomaki P, Mecklin JP, Jarvinen HJ. Cancer risk in mutation carriers of DNA-mismatch-repair genes. Int J Cancer. 1999; 81(2):214-218. [PubMed: 10188721]

2. Umar A, Boland CR, Terdiman JP, Syngal S, de la Chapelle A, Ruschoff J, Fishel R, Lindor NM, Burgart LJ, Hamelin R, et al. Revised Bethesda Guidelines for hereditary nonpolyposis colorectal cancer (Lynch syndrome) and microsatellite instability. J Natl Cancer Inst. 2004; 96(4):261-268. [PubMed: 14970275]

3. Lynch HT, de la Chapelle A. Genetic susceptibility to non-polyposis colorectal cancer. J Med Genet. 1999; 36(11):801-818. [PubMed: 10544223] 
4. Lynch HT, Lynch J. Lynch syndrome: genetics, natural history, genetic counseling, and prevention. J Clin Oncol. 2000; 18(21 Suppl):19S-31S. [PubMed: 11060321]

5. Plaschke J, Engel C, Kruger S, Holinski-Feder E, Pagenstecher C, Mangold E, Moeslein G, Schulmann K, Gebert J, von Knebel Doeberitz M, et al. Lower incidence of colorectal cancer and later age of disease onset in 27 families with pathogenic MSH6 germline mutations compared with families with MLH1 or MSH2 mutations: the German Hereditary Nonpolyposis Colorectal Cancer Consortium. J Clin Oncol. 2004; 22(22):4486-4494. [PubMed: 15483016]

6. Vasen HF. Clinical description of the Lynch syndrome [hereditary nonpolyposis colorectal cancer (HNPCC)]. Fam Cancer. 2005; 4(3):219-225. [PubMed: 16136381]

7. Vasen HF, Wijnen JT, Menko FH, Kleibeuker JH, Taal BG, Griffioen G, Nagengast FM, MeijersHeijboer EH, Bertario L, Varesco L, et al. Cancer risk in families with hereditary nonpolyposis colorectal cancer diagnosed by mutation analysis. Gastroenterology. 1996; 110(4):1020-1027. [PubMed: 8612988]

8. Vasen HF, Mecklin JP, Khan PM, Lynch HT. The International Collaborative Group on Hereditary Non-Polyposis Colorectal Cancer (ICG-HNPCC). Dis Colon Rectum. 1991; 34(5):424-425. [PubMed: 2022152]

9. Vasen HF, Watson P, Mecklin JP, Lynch HT. New clinical criteria for hereditary nonpolyposis colorectal cancer (HNPCC, Lynch syndrome) proposed by the International Collaborative group on HNPCC. Gastroenterology. 1999; 116(6):1453-1456. [PubMed: 10348829]

10. Rodriguez-Bigas MA, Boland CR, Hamilton SR, Henson DE, Jass JR, Khan PM, Lynch H, Perucho M, Smyrk T, Sobin L, et al. A National Cancer Institute Workshop on Hereditary Nonpolyposis Colorectal Cancer Syndrome: meeting highlights and Bethesda guidelines. J Natl Cancer Inst. 1997; 89(23):1758-1762. [PubMed: 9392616]

11. Dunlop MG, Farrington SM, Carothers AD, Wyllie AH, Sharp L, Burn J, Liu B, Kinzler KW, Vogelstein B. Cancer risk associated with germline DNA mismatch repair gene mutations. Hum Mol Genet. 1997; 6(1):105-110. [PubMed: 9002677]

12. Durno C, Aronson M, Bapat B, Cohen Z, Gallinger S. Family history and molecular features of children, adolescents, and young adults with colorectal carcinoma. Gut. 2005; 54(8):1146-1150. [PubMed: 15845562]

13. Farrington SM, Lin-Goerke J, Ling J, Wang Y, Burczak JD, Robbins DJ, Dunlop MG. Systematic analysis of hMSH2 and hMLH1 in young colon cancer patients and controls. Am J Hum Genet. 1998; 63(3):749-759. [PubMed: 9718327]

14. Liu B, Farrington SM, Petersen GM, Hamilton SR, Parsons R, Papadopoulos N, Fujiwara T, Jen J, Kinzler KW, Wyllie AH, et al. Genetic instability occurs in the majority of young patients with colorectal cancer. Nat Med. 1995; 1(4):348-352. [PubMed: 7585065]

15. Terdiman JP, Levin TR, Allen BA, Gum JR Jr, Fishbach A, Conrad PG, Miller GA, Weinberg V, Bachman R, Bergoffen J, et al. Hereditary nonpolyposis colorectal cancer in young colorectal cancer patients: high-risk clinic versus population-based registry. Gastroenterology. 2002; 122(4): 940-947. [PubMed: 11910346]

16. Kerber RA, Neklason DW, Samowitz WS, Burt RW. Frequency of familial colon cancer and hereditary nonpolyposis colorectal cancer (Lynch syndrome) in a large population database. Fam Cancer. 2005; 4(3):239-244. [PubMed: 16136384]

17. Hampel H, Frankel WL, Martin E, Arnold M, Khanduja K, Kuebler P, Nakagawa H, Sotamaa K, Prior TW, Westman J, et al. Screening for the Lynch syndrome (hereditary nonpolyposis colorectal cancer). N Engl J Med. 2005; 352(18):1851-1860. [PubMed: 15872200]

18. Lynch HT, Lynch PM. Molecular screening for the Lynch syndrome--better than family history? N Engl J Med. 2005; 352(18):1920-1922. [PubMed: 15872208]

19. Southey MC, Jenkins MA, Mead L, Whitty J, Trivett M, Tesoriero AA, Smith LD, Jennings K, Grubb G, Royce SG, et al. Use of molecular tumor characteristics to prioritize mismatch repair gene testing in early-onset colorectal cancer. J Clin Oncol. 2005; 23(27):6524-6532. [PubMed: 16116158]

20. Halvarsson B, Lindblom A, Rambech E, Lagerstedt K, Nilbert M. Microsatellite instability analysis and/or immunostaining for the diagnosis of hereditary nonpolyposis colorectal cancer? Virchows Arch. 2004; 444(2):135-141. [PubMed: 14652751] 
21. Hendriks YM, Wagner A, Morreau H, Menko F, Stormorken A, Quehenberger F, Sandkuijl L, Moller P, Genuardi M, Van Houwelingen H, et al. Cancer risk in hereditary nonpolyposis colorectal cancer due to MSH6 mutations: impact on counseling and surveillance. Gastroenterology. 2004; 127(1):17-25. [PubMed: 15236168]

22. Wagner A, Hendriks Y, Meijers-Heijboer EJ, de Leeuw WJ, Morreau H, Hofstra R, Tops C, Bik E, Brocker-Vriends AH, van Der Meer C, et al. Atypical HNPCC owing to MSH6 germline mutations: analysis of a large Dutch pedigree. J Med Genet. 2001; 38(5):318-322. [PubMed: 11333868]

23. Pinto C, Veiga I, Pinheiro M, Mesquita B, Jeronimo C, Sousa O, Fragoso M, Santos L, MoreiraDias L, Baptista M, et al. MSH6 germline mutations in early-onset colorectal cancer patients without family history of the disease. Br J Cancer. 2006; 95(6):752-756. [PubMed: 16940983]

24. Croitoru ME, Cleary SP, Di Nicola N, Manno M, Selander T, Aronson M, Redston M, Cotterchio M, Knight J, Gryfe R, et al. Association between biallelic and monoallelic germline MYH gene mutations and colorectal cancer risk. J Natl Cancer Inst. 2004; 96(21):1631-1634. [PubMed: 15523092]

25. Jo WS, Bandipalliam P, Shannon KM, Niendorf KB, Chan-Smutko G, Hur C, Syngal S, Chung DC. Correlation of polyp number and family history of colon cancer with germline MYH mutations. Clin Gastroenterol Hepatol. 2005; 3(10):1022-1028. [PubMed: 16234049]

26. Neklason DW, Stevens J, Boucher KM, Kerber RA, Matsunami N, Barlow J, Mineau G, Leppert MF, Burt RW. American founder mutation for attenuated familial adenomatous polyposis. Clin Gastroenterol Hepatol. 2008; 6(1):46-52. [PubMed: 18063416]

27. Wang L, Baudhuin LM, Boardman LA, Steenblock KJ, Petersen GM, Halling KC, French AJ, Johnson RA, Burgart LJ, Rabe K, et al. MYH mutations in patients with attenuated and classic polyposis and with young-onset colorectal cancer without polyps. Gastroenterology. 2004; 127(1): 9-16. [PubMed: 15236166]

28. Wong P, Verselis SJ, Garber JE, Schneider K, DiGianni L, Stockwell DH, Li FP, Syngal S. Prevalence of early onset colorectal cancer in 397 patients with classic Li-Fraumeni syndrome. Gastroenterology. 2006; 130(1):73-79. [PubMed: 16401470]

\section{Appendix}

Revised Bethesda guidelines

Requires at least one of the following:

I. CRC diagnosed in a patient who is less than 50 years of age

II. Presence of synchronous, metachronous CRC, or other associated tumor *

III. CRC diagnosed in a patient who is less than 60 years of age with the presence of tumor infiltrating lymphocytes, Crohn's-like lmphocytic reaction, mucinous/signet-ring differentiation, and/or medullary growth pattern

IV. CRC in a patient and one or more first degree relatives with an associated tumor ${ }^{*}$, with at least one of the cancers being diagnosed under age 50 years

V. CRC in a patient and two or more first or second degree relatives with associated tumors ${ }^{*}$, regardless of age

CRC, Colorectal cancer

colorectal, endometrial, stomach, ovarian, pancreas, ureter, renal pelvis, biliary tract, small bowel and brain cancers, sebaceous gland cancers and adenomas, and keratoacanthomas 
Clinicalpathological characteristics and demographics of probands

\begin{tabular}{|c|c|c|c|c|c|}
\hline $\begin{array}{l}\text { Characteristics and criteria } \\
\text { met }\end{array}$ & $\operatorname{COH}(n=26)$ & HCI $(n=33)$ & MDA $(n=37)$ & Combined $(\mathrm{n}=96)$ & $\begin{array}{l}\text { P-value } \\
\text { COH vs } \\
\text { HCI vs } \\
\text { MDA }\end{array}$ \\
\hline Female & $17(65.4 \%)$ & $18(54.5 \%)$ & $18(48.6 \%)$ & $53(55.2 \%)$ & 0.420 \\
\hline Male & $9(34.6 \%)$ & $15(45.5 \%)$ & $19(51.4 \%)$ & $43(44.8 \%)$ & \\
\hline Mean age of diagnosis (range) & $29.4(19-35)$ & $29.7(18-35)$ & $29.2(18-35)$ & $29.4(18-35)$ & 0.920 \\
\hline Right sided cancer ${ }^{*}$ & $11 / 24(45.8 \%)$ & $9 / 33(27.3 \%)$ & $22 / 37(59.5 \%)$ & $42 / 94(44.7 \%)$ & 0.026 \\
\hline Associated histology ${ }^{\dagger}$ & $8 / 23(34.8 \%)$ & $14 / 32(43.8 \%)$ & $9 / 35(25.7 \%)$ & $31 / 90(34.4 \%)$ & 0.300 \\
\hline Single case indicator ${ }^{t}$ & $17 / 26(65.4 \%)$ & $16 / 26(61.5 \%)$ & $15 / 37(40.5 \%)$ & $48 / 89(53.9 \%)$ & 0.098 \\
\hline $\begin{array}{l}\text { Revised Bethesda guideline II, } \\
\text { IV, and/or V }\end{array}$ & $7 / 26(26.9 \%)$ & $5 / 26(19.2 \%)$ & $13 / 37(35.1 \%)$ & $25 / 89(28.1 \%)$ & 0.380 \\
\hline Amsterdam criteria I and/or II & $2 / 26(7.7 \%)$ & $5 / 26(19.2 \%)$ & 9/37 (24.3\%) & $16 / 89(18.0 \%)$ & 0.234 \\
\hline
\end{tabular}

$\mathrm{COH}$, City of Hope; HCI, Huntsman Cancer Institute; MDA, MD Anderson

*ocated proximal to the splenic flexure

${ }^{\dagger}$ Tumor infiltrating lymphocytes, Crohn's-like lymphocytic reaction, mucinous/signet ring cell carcinoma, or medullary growth pattern

Did not meet revised Bethesda II, IV, or V or Amsterdam criteria I or II 


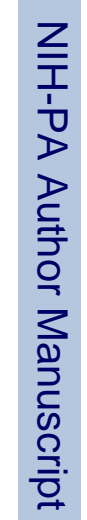

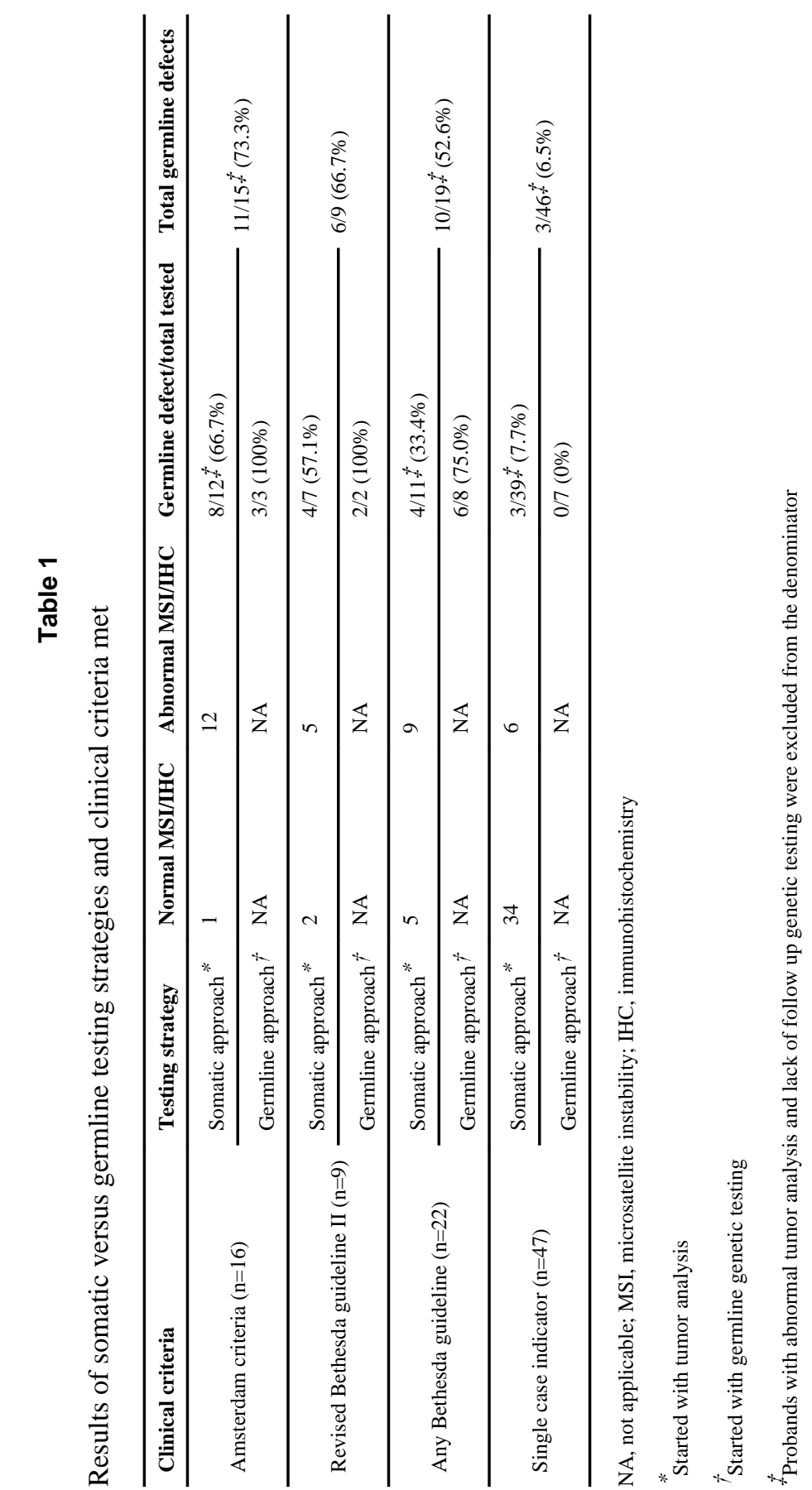

Fam Cancer. Author manuscript; available in PMC 2013 April 08. 


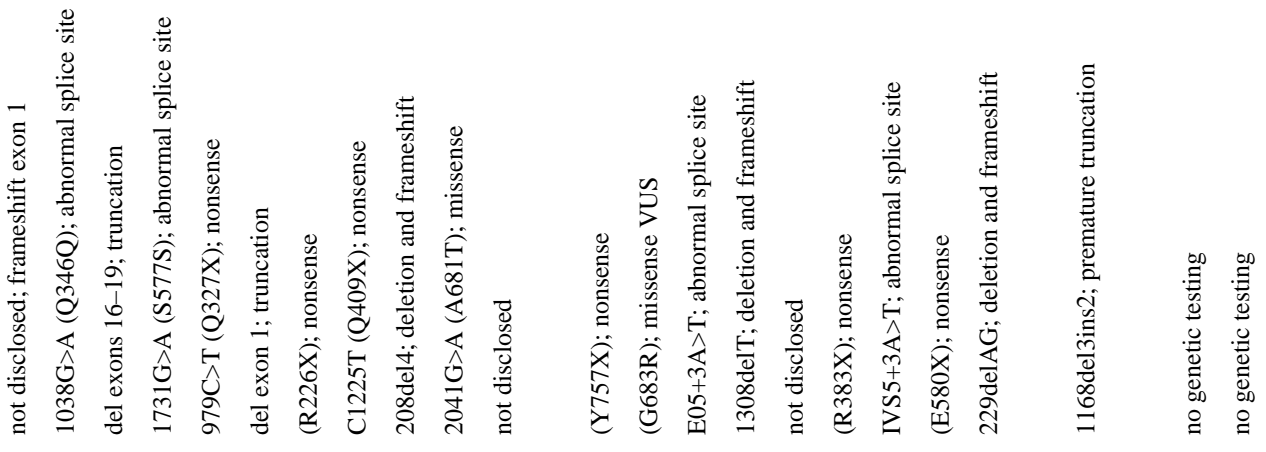

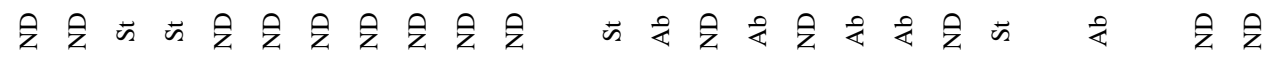

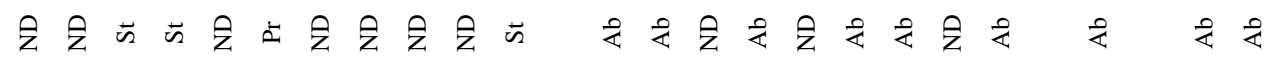

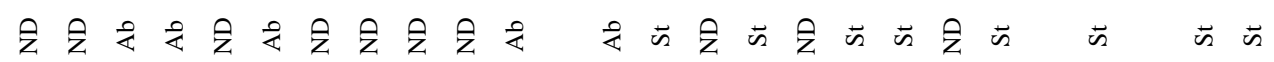

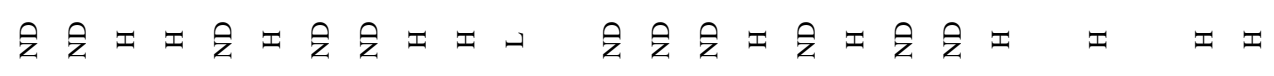




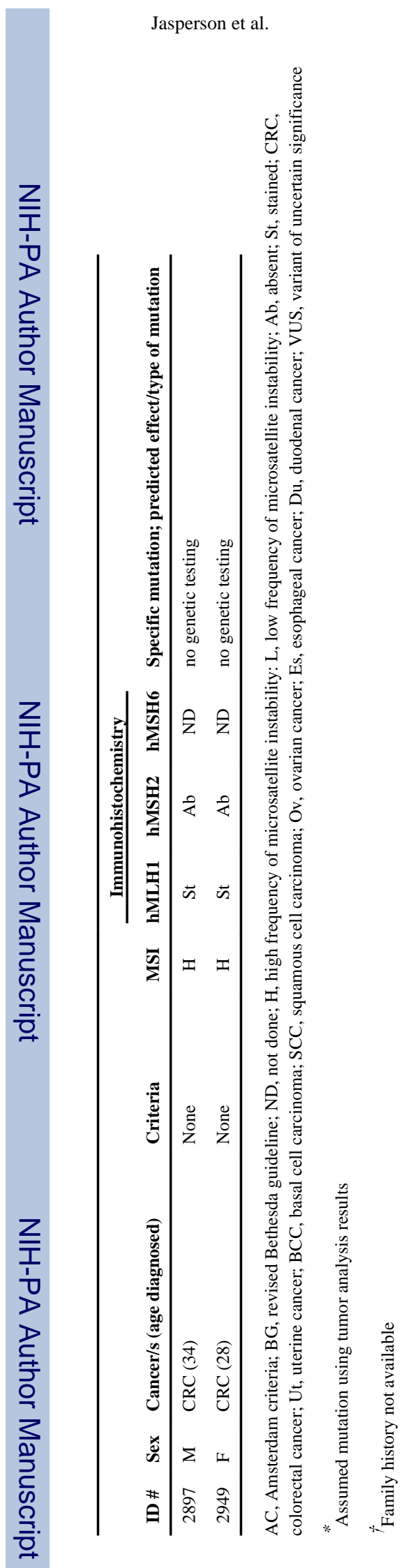

Page 13 
Table 3

Differential diagnoses

\begin{tabular}{|c|c|c|c|c|}
\hline ID \# & Cancer (age diagnosed) & Lynch syndrome results & Family history (age diagnosed y) & Additional testing \\
\hline 201 & Colon cancer (33) & 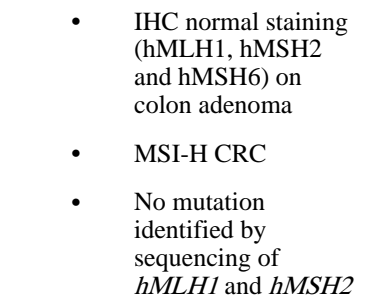 & $\begin{array}{ll}\text { - } & \begin{array}{l}\text { Brother with fundic gland } \\
\text { and colonic polyposis (36) }\end{array} \\
\text { - } & \text { Sister CRC and Ut (43) } \\
\text { - } & \text { Mother CRC (57) } \\
\text { - } & \text { Maternal aunt CRC (50) } \\
\text { - } & \begin{array}{l}\text { Maternal cousin CRC } \\
\text { (30s) }\end{array}\end{array}$ & $\begin{array}{l}A P C \text { genetic testing in } \\
\text { brother with polyposis } \\
\text { revealed a deleterious } \\
\text { germline deletion in exon } \\
4\end{array}$ \\
\hline 218 & $\begin{array}{l}\text { Osteosarcoma (14) and } \\
\text { colon cancer (34) }\end{array}$ & $\begin{array}{l}\text { IHC normal staining } \\
\text { (hMLH1, hMSH2 } \\
\text { and hMSH6) }\end{array}$ & $\begin{array}{ll}\text { - } & \text { Father prostate cancer (61) } \\
\text { - } & \text { Paternal uncle CRC (47) } \\
\text { - } & \begin{array}{l}\text { Paternal grandfather lung } \\
\text { and prostate cancer (?) }\end{array} \\
\text { - } & \text { Paternal grandmother } \\
\text { breast cancer (63) }\end{array}$ & $\begin{array}{l}\text { Proband had genetic } \\
\text { testing of TP53 and a } \\
\text { deleterious germline } \\
\text { mutation was identified }\end{array}$ \\
\hline
\end{tabular}

IHC, immunohistochemistry; MSI-H, high level of microsatellite instability; CRC, colorectal cancer; Ut, uterine cancer 
Table 4

Early onset colorectal cancer studies

\begin{tabular}{|c|c|c|c|c|}
\hline Study & Age of CRC & Population & Tumor analysis results & $\begin{array}{c}\text { Germline mutations identified/ } \\
\text { total tested }\end{array}$ \\
\hline Liu (1995) & $<36$ & $\begin{array}{l}\text { Unselected CRC surgical patients (US } \\
\text { and Scotland) }\end{array}$ & $\begin{array}{l}8 / 31(25.8 \%) \\
\text { MSI-H }\end{array}$ & $5 / 12(41.7 \%) h M L H 1$ or $h M S H 2$ \\
\hline Dunlop (1997) & $<36$ & Scottish National Cancer Registry & $\begin{array}{l}13 / 23(56.5 \%) \\
\text { MSI-H }\end{array}$ & 6/13 (46.2\%) $h M L H 1$ or $h M S H 2$ \\
\hline Farrington (1998) & $<30$ & Cancer registries (Scotland) & $\begin{array}{l}19 / 40(47.5 \%) \\
\text { MSI-H }\end{array}$ & $14 / 50(28.0 \%) h M L H 1$ or $h M S H 2$ \\
\hline \multirow{2}{*}{ Terdiman (2002) } & $<36$ & High risk CRC clinic (US) & $\begin{array}{l}28 / 40(70.0 \%) \\
\text { MSI-H }\end{array}$ & $13 / 21(61.9 \%) h M L H 1$ or $h M S H 2$ \\
\hline & $<36$ & Population based cancer registry (US) & $\begin{array}{l}\text { 6/18 (33.3\%) } \\
\text { MSI-H }\end{array}$ & $0 / 16(0 \%) h M L H 1$ or $h M S H 2$ \\
\hline Durno (2005) & $<25$ & Familial cancer registry (Canada) & $\begin{array}{l}\text { 8/11 (72.7\%) } \\
\text { MSI-H }\end{array}$ & $\begin{array}{c}\text { 6/14 (42.9\%) hMLH1, hMSH2, or } \\
\text { hPMS2 (Only one person tested for } \\
\text { hPMS2 mutations) }\end{array}$ \\
\hline
\end{tabular}

CRC, colorectal cancer; MSI-H, high microsatellite instability; US, United States 